\title{
THE SIMPLIFIED ANALYSIS OF THE ASYMMETRIC SINGLE-PYLON SUSPENSION BRIDGE WITH RIGID CABLES
}

\author{
Tatjana GRIGORJEVA (D ${ }^{1^{*}}$, Ainars PAEGLITIS (D2 \\ ${ }^{1}$ Vilnius Gediminas Technical University, Sauletekio al. 11 LT-10223 Vilnius, Lithuania \\ ${ }^{2}$ Rigas Technical University, Kalku str. 1, LV-1658 Riga, Latvia
}

Received 14 October 2020; accepted 22 April 2021

\begin{abstract}
Suspension bridges are characterized by exceptional architectural expressions and excellent technical and economic properties. However, despite all advantages, suspension bridges have a few negative features. Suspension bridges with flexible cables share excessive deformation caused by the displacement of kinematic origin. In order to increase the stiffness of suspension bridges, an innovative structural solution refers to rigid cables used instead of the flexible ones. The paper describes a methodology for calculating an asymmetric single-pylon suspension bridge with rigid cables considering installation features. Also, the article presents the numerical simulation of the bridge and determines the accuracy of the proposed methodology.
\end{abstract}

Keywords: suspension bridge, flexible cable, rigid cable, exact analysis, simplified analysis, construction method.

\section{Introduction}

The structures of suspension bridges are characterized by the high effectiveness of overlapping large spans and exceptional architectural expression (Gimsing \& Georgakis, 2012; Ryall et al., 2000; Troyano, 2003). The main drawback of analogous bridges includes excessive deformation due to the displacement of kinematic origin and is greatly affected by asymmetric loading (Kiisa et al., 2012; Kulbach, 2007; Sandovič et al., 2011). Thus, a sufficient variety of structural measures have been proposed to reduce the occurring kinematic displacements (Juozapaitis et al., 2015; Goremkins et al., 2012; Jennings, 1987; Strasky, 2005). A huge number of analytical calculation methods for classical suspension bridges with flexible cables are based on nonlinear calculation in line to the deformed scheme (Arco \& Aparicio, 2001; Clemente et al., 2000; Gimsing \& Georgakis, 2012; Idnurm, 2006; Jennings, 1987; Kim \& Thai, 2010; Kulbach, 2007; Wollmann, 2001). Extensive research refers to examining the dynamic characteristics of suspension bridges (Goremkins et al., 2013; Sousa et al., 2011; Treyssede, 2010).

The calculation of the suspension bridge assumes that the main cable is absolutely flexible, i.e. has no flexural rigidity and is equal to $E I_{c}=0$. The made assumption is partly valid for analysing the complete structure of the bridge, but local flexure occurs above the pylons and at the attachment points of flexible cables and hangers. The methods for calculating and analysing classical suspension bridges with flexible cables for estimating local flexure are discussed in works by (Caballero \& Pose, 2010; Furst et al., 2001; Gimsing \& Georgakis, 2012; Juozapaitis \& Norkus, 2005, 2007). The authors of the article (Prato \& Ceballos, 2003) also pointed out the behavioural peculiarities of the main cables of suspension bridges and identified they were subject to the structure of the anchors of the cables and sufficiently large bending moments taking place at the bearing sections. Hence, a structural method for reducing the bending moments of the bearing sections of the main cables has been proposed.

The use of rigid cables is one of the methods for ensuring the stiffness of the suspension bridge and for reducing kinematic displacements (Grigorjeva et al., 2010a; Juozapaitis et al. 2010, 2013). The simplified methodology for calculating the classical symmetric single-span bridge with rigid cables is provided in (Grigorjeva et al., 2010a). The article by (Grigorjeva \& Juozapaitis, 2013) reports a revised methodology for symmetric single-span suspension bridges with rigid cables. The exact calculation methods of classical symmetric suspension bridges with rigid cables

${ }^{*}$ Corresponding author. E-mail: tatjana.grigorjeva@vilniustech.lt 
are discussed in (Juozapaitis et al. 2010, 2013). Rigid cable means a rigid element made from rolled steel profiles or trusses like the Tower Bridge in London.

The suspension bridges with the cables of finite flexural stiffness are built in several ways. The first technique involves the erected pylons where the cable of finite flexural rigidity is assembled from individual elements the joints of which form rigid components. After installing the rigid cable, hangers and a stiffening girder are built-in. The second method of building and installing the suspension bridge with the cables of finite flexural rigidity covers the fixed pylons where the rigid cable is produced from separate flexibly connected elements. At this stage, cable behaviour corresponds to the performance of an absolutely flexible cable. After installing the cable, hangers and the stiffening girder are built-in. The cable treated as flexible is subjected to symmetric self-weighed and built-in loads. Before loading the bridge with operational loads, the interconnection components of the individual elements of the cable are 'stiffened' thus giving rigidity for flexure. The methods for calculating the symmetric, two-pylon suspension bridge with respect to the installation stages of suspension bridges with rigid cables are presented in (Grigorjeva et al., 2010b).

The paper provides the simplified calculation methodology for the asymmetric single-pylon suspension bridge with rigid cables considering the effects of symmetric and asymmetric loading and applying the second installation method where the cable is completely flexible under symmetric installation loads and the components of the individual segments of the cable are stiffened before loading it with operational loads. The proposed methodology is versatile and easily applied to the simplified calculation of asymmetric single-pylon suspension bridges with flexible cables at the initial stage of design. The article also compares the results of the discussed methodology for calculating bridges with rigid cables with the findings of numerical simulation and determines the accuracy of the suggested methodology.

\section{The simplified analysis of the asymmetric single-pylon suspension bridge with rigid cables under symmetric loading}

The proposed simplified methodology for the asymmetric single-pylon suspension bridge is based on the techniques for calculating the classical suspension bridge with rigid cables and has been put forward by the authors of the article (Grigorjeva et al., 2010a; Grigorjeva \& Juozapaitis, 2013). The above introduced fairly simple engineering calculation method is in consonance to the deformed scheme and refers to the following assumptions:

- only static loads act on the bridge structure;

- the behaviour of the structure is elastic;

- the static load is evenly distributed on the stiffening girder over the entire span of the bridge;

- the static load is evenly transferred to the rigid cable via hangers;

- hangers do not extend.

Figure 1 shows an overview and calculation scheme of the asymmetric single-pylon suspension bridge. The rigid cable is subjected to dead symmetric load $g$ and a part of live symmetric load pc. The stiffening girder takes a part of live symmetric load $p_{b}$. The total live load is $p$.

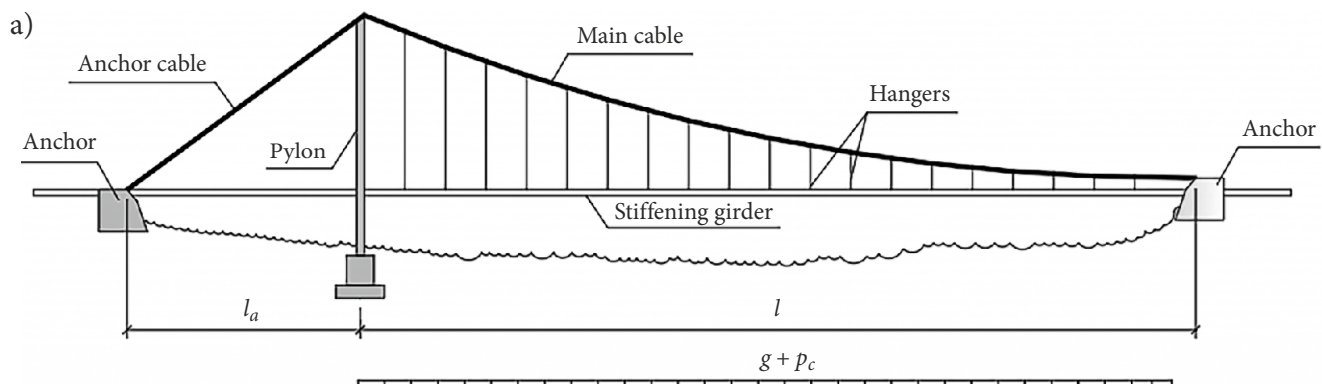

b)

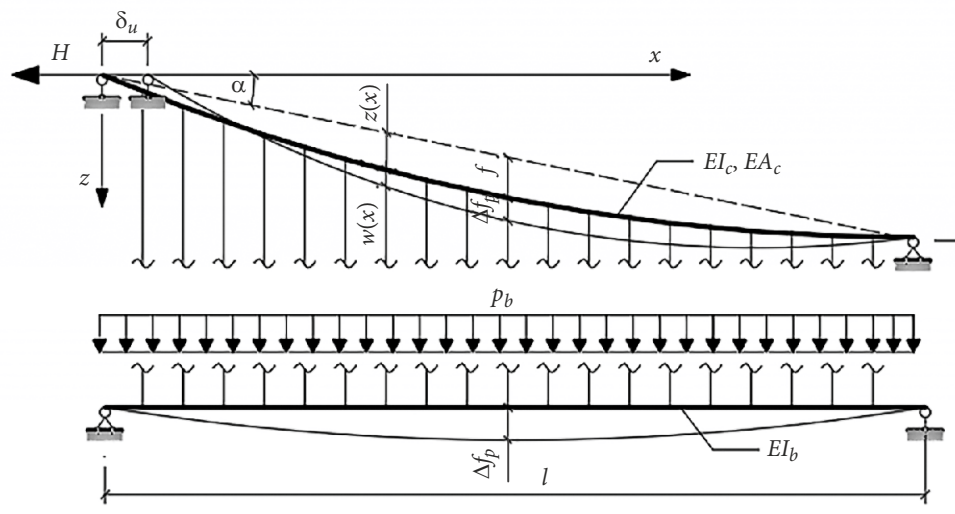

Figure 1. A single-pylon asymmetric suspension bridge: $\mathrm{a}$ - general view; b - calculation model 
At the beginning of building the bridge, the cable is considered to be completely flexible under the action of the personal weight and a dead evenly distributed load. An increment in the sag of the cable under the dead load is equal to $\Delta f_{g}=0$. The thrust of the flexible cable under the dead load is calculated as follows:

$$
H_{g} \cong \frac{g l^{2}}{8 f}
$$

where $f$ - the initial sag of the cable under symmetric dead loads.

Prior to loading the bridge with operational loads, the interconnection components of the individual elements of the cable are 'stiffened' thus giving rigidity for flexure. A part $p_{c}$ of live load $p$ falls on the rigid cable and a part of load $p_{b}$ - on the stiffening girder.

Considering individual flexural rigidity, the thrust of the rigid cable following deformation is equal to

$$
H_{g+p}=\frac{\left(g+p_{c}\right) l^{2}}{8\left(f+\Delta f_{p}\right)}-\frac{48 f E I_{c}}{5 l^{2}\left(f+\Delta f_{p}\right)},
$$

where $E I_{c}$ - the flexural rigidity of the rigid cable (Grigorjeva \& Juozapaitis, 2013), $\Delta f_{p}$ - the deflection of the cable under a part of live load $p_{c}$.

Under the action of the live load, the length of the rigid cable increases and makes

$$
\Delta S=\frac{\left(H_{g+p}-H_{g}\right) \cdot l}{E A_{c}},
$$

where $E A_{c}$ - the axial stiffness of the cable.

The coherence equation of the deformation of the rigid cable at different levels equals

$$
S_{1}=S_{0}+\Delta S,
$$

$S_{1}=S_{0}+\Delta S$
where $S_{1}=\frac{l}{\cos \alpha}-\delta_{u}+\frac{8}{3} \frac{\left(f+\Delta f_{p}\right)^{2}}{l} \cos ^{3} \alpha-$ the length of the rigid cable following deformation considering the maximum permissible displacement at the top of the pylon $\delta_{u}, S_{0}=\frac{l}{\cos \alpha}+\frac{8}{3} \frac{f^{2}}{l} \cos ^{3} \alpha-$ the initial length of the
cable.

Solving Equations (4), (1) and (2) and the estimation of a part of the load on the stiffening girder show that $p_{c}=p-\frac{76,8 E I_{b} \Delta f_{p}}{l^{4}}$, where $E I_{b}-$ the flexural rigidity of the stiffening girder (Grigorjeva \& Juozapaitis, 2013). The obtained displacement in the middle of the span is equal to

$$
\Delta f_{p} \cong \frac{0,375 p l^{4}-3 l^{2} H_{g} f+3 \delta_{u} f l E A_{c}}{16 f^{2} E A_{c} \cos ^{3} \alpha+28,8 E I_{c}+28,8 E I_{b}+3 H_{g} l^{2}-3 \delta_{u} l E A_{c}} .
$$

The sag of the span of the cable under the action of live load $\Delta f_{p}$ allows determining the distribution of live load $p$ between the cable and the girder and identifying strain and internal forces of the rigid cable and the girder.
The maximum bending moment of the cable having finite flexural rigidity is equal to

$$
M_{c}=\frac{48 \Delta f_{p} E I_{c}}{5 l^{2}} .
$$

The maximum total strain of the cable having finite flexural rigidity equals

$$
\sigma_{c}=\sigma_{N}+\sigma_{M}=\frac{p_{c} l^{2}}{8\left(f+\Delta f_{p}\right) A_{c}}-\frac{48 E I_{c}}{5 l^{2} A_{c}}+\frac{48 \Delta f_{p} E I_{c}}{5 l^{2} W_{c}} .
$$

The maximum bending moment of the stiffening girder under the live load and the maximum strain of the stiffening girder are determined using simple formulas $M_{b}=\frac{p_{b} l^{2}}{8}$ and $\sigma_{b}=\frac{M_{b}}{W_{b}}$.

\section{The simplified analysis of the asymmetric single-pylon suspension bridge with rigid cables under asymmetric loading}

Under asymmetric loading, the calculation of the suspension bridge with rigid cables is performed at two stages. At the first stage, similarly to symmetric loading, the cable is treated as completely flexible. An increment in the sag of the cable under the dead load is equal to $\Delta f_{g}=0$. The stiffening girder is loaded with half the live load and equals $p_{I}=0.5 p$.

Considering the elongation of the cable and the displacement at the top of the pylon, a consistent equation of deformation (4) of the rigid cable with trusses at different levels is as follows:

$$
\begin{aligned}
& \frac{8}{3} \frac{\left(f+\Delta f_{p, I}\right)^{2}}{l} \cos ^{3} \alpha-\delta_{u}= \\
& \frac{8}{3} \frac{f^{2}}{l} \cos ^{3} \alpha+\frac{\left(H_{g+p, I}-H_{g}\right) \cdot l}{E A_{c}} .
\end{aligned}
$$

The built-in bridge structure adds live load $p_{I}$ a part of which is attributed to cable $p_{c, I}$ and the other part is taken by stiffening girder $p_{b, I}$.

Conforming to flexural rigidity, the thrust of the rigid cable after deformation is equal to

$$
H_{g+p, I}=\frac{\left(g+p_{c, I}\right) l^{2}}{8\left(f+\Delta f_{p}\right)}-\frac{48 f E I_{c}}{5 l^{2}\left(f+\Delta f_{p}\right)},
$$

where $\Delta f_{p, I}$ - the deflection of the cable under a part of live load $p_{c, I}$.

Solving Equations (10), (1) and (11) and the estimation of a part of the load on the cable show that $p_{c, I}=p_{I}-\frac{76,8 E I_{b} \Delta f_{p, I}}{l^{4}}$. The obtained displacement in the middle of the span is equal to

$$
\Delta f_{p, I} \cong \frac{0,375 p_{I} l^{4}-3 l^{2} H_{g} f+3 \delta_{u} f l E A_{c}}{16 f^{2} E A_{c} \cos ^{3} \alpha+28,8 E I_{c}+28,8 E I_{b}+3 H_{g} l^{2}-3 \delta_{u} l E A_{c}} .
$$


An increment in the sag of the middle of the span $\Delta f_{p, I}$ allows determining a part of the live load on the stiffening girder taking a part of load $p_{b, I}$ :

$$
p_{b, I}=\frac{76,8 E I_{b} \Delta f_{p, I}}{l^{4}}
$$

At the second stage, half the span is loaded with the live load in the opposite direction $p_{I I}=0,5 p$ (Figure 2). The left part of the span takes the direction of the acting load downwards, and the right part goes upwards.

It is assumed that the values of an increment in the initial sag in the middle of the span $\Delta f_{p, I}$ and thrust $H_{g+p, I}$ remain the same and makes it possible to determine the distribution of live load $p_{I I}$ between the stiffening girder and the rigid cable.

Loading half the span with the live load in the opposite direction $p_{I I}=0,5 p$ shows that the rigid cable takes a part of load $p_{c, I I}$, whereas the other share is attributed to stiffening girder $p_{b, I I}=p_{I I}-p_{c, I I}$ (Grigorjeva et al., 2010b):

$$
p_{c, I I}=\frac{\frac{5 p_{I I} a^{4}}{384 E I_{b}}+\frac{f}{4}-\frac{p_{c, I} a^{2}}{8 H_{g+p, I}}}{\frac{5 c^{4}}{384 E I_{b}}+\frac{a^{2}}{8 H_{g+p, I}}} .
$$

With reference to $p_{c, I}, p_{c, I I}$ and in line to Equations (8) and (7), the values of $\Delta f_{p}$ and $H$ are specified employing the load attributed to $p_{c}=p_{c, I}+p_{c, I I}$ instead of load $p_{I}$. The distribution of loads between the cable and the stiffening girder allows easily calculating the displacements and internal forces in these elements.

The maximum displacement of the loaded part of the bridge $w_{l}$ is calculated as follows:

$$
w_{l}=\frac{\left(p_{c, I}+p_{c, I I}\right) \cdot a^{2}}{8 H_{g+p, I}}-\frac{f}{4} .
$$

The maximum displacement of the unloaded part of the bridge $w_{l}$ is calculated as follows:

$$
w_{r}=\frac{\left(p_{c, I}-p_{c, I I}\right) \cdot a^{2}}{8 H_{g+p, I}}-\frac{f}{4} .
$$

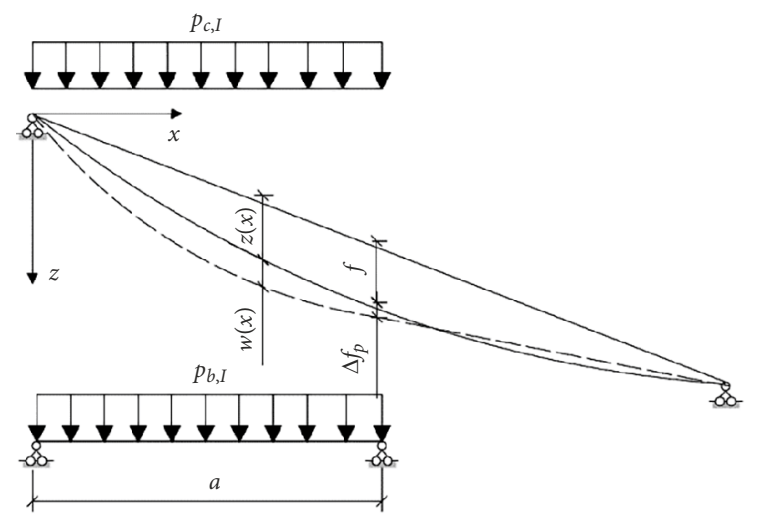

Figure 2. The calculation scheme under asymmetric loading at the second stage of calculation

\section{The simplified analysis of the asymmetric single-pylon suspension bridge with flexible cables}

The first chapter describes the versatility of the single-pylon asymmetric suspension bridge with rigid cables. The structure of the bridge is easily applicable to the simplified calculation of asymmetric suspension bridges with flexible cables and to the preliminary selection of the geometric characteristics of the elements constituting the bridge.

An increment in the sag of the cable under the dead load is equal to $\Delta f_{g}=0$. The thrust of the flexible cable under the dead load is calculated in line to (1).

The thrust of the flexible cable following deformation is equal to

$$
H_{g+p}=\frac{\left(g+p_{c}\right) l^{2}}{8\left(f+\Delta f_{p}\right)}
$$

Similarly to the case of the bridge with rigid cables, for solving equation (4), considering the thrust of the flexible cable under dead load $H_{g}(1)$ and thrust after deformation $H_{g+p}$ calculated in consonance to formula (8) assists in obtaining the displacement in the middle of the span thus estimating only the flexural rigidity of the stiffening girder:

$$
\Delta f_{p} \cong \frac{0,375 p l^{4}-3 l^{2} H_{g} f+3 \delta_{u} f l E A_{c}}{16 f^{2} E A_{c} \cos ^{3} \alpha+28,8 E I_{b}+3 H_{g} l^{2}-3 \delta_{u} l E A_{c}},
$$

Likewise in the case of the flexible cable, the application of simple expressions helps with determining the stress/strain state of the bridge with flexible cables.

\section{A comparison of the results of the simplified analysis of the single-pylon suspension bridge with rigid cables performing Fe simulation}

In order to determine the accuracy of the proposed simplified methodology for calculating the single-pylon asymmetric suspension bridge with rigid cables, numerical simulation has been performed using the finite element method. MIDAS/Civil software has been chosen for calculations.

The main span of the bridge is $50 \mathrm{~m}$, the initial sag of the middle span of the cable is $5 \mathrm{~m}$ and the distance between hangers is $2.5 \mathrm{~m}$. The total flexural rigidity of the bridge is $E I=4.2 \cdot 10^{4} \mathrm{kNm} 2$ and the ratio of the flexural rigidity of the cable to the flexural rigidity of the stiffening girder is $\xi=1.0$. The cable is loaded with evenly distributed dead load g, half the stiffening girder is loaded with live load $\mathrm{p}$ and the ratio of the live to dead load is $\gamma=1$.

The peculiarities of simulating suspension bridges with rigid cables in the MIDAS/Civil environment were discussed by (Grigorjeva \& Juozapaitis, 2013). At the beginning of the numerical experiment, employing procedures established in MIDAS/Civil software and focused on calculating suspension bridges assists in determining the initial stress/strain state of the bridge under the effect of dead load $\mathrm{g}$. 
Table 1. A comparison of the values of parameters computed using the analytical method and predicted by FE simulation

\begin{tabular}{|c|c|c|c|}
\hline Parameter & Computed using the analytical method & Predicted by FE simulation & Ratio of computed to predicted \\
\hline \multicolumn{4}{|c|}{ Symmetric loading } \\
\hline$\Delta f_{p}, \mathrm{~m}$ & 0.037 & 0.035 & 1.05 \\
\hline $\mathrm{H}, \mathrm{kN}$ & 1218 & 1225 & 0.99 \\
\hline $\begin{array}{l}\text { Mc,max, } \mathrm{kNm} \\
\mathrm{Mb}, \max , \mathrm{kNm}\end{array}$ & 5.90 & 5.60 & 1.05 \\
\hline$\sigma_{c, \text { max }}, \mathrm{MPa}$ & 88.2 & 84.4 & 1.05 \\
\hline$\sigma_{b, \text { max }}, \mathrm{MPa}$ & 3.90 & 3.80 & 1.03 \\
\hline \multicolumn{4}{|c|}{ Asymmetric loading } \\
\hline$w_{l}, \mathrm{~m}$ & 0.261 & 0.230 & 1.13 \\
\hline$w_{r}, \mathrm{~m}$ & -0.196 & -0.176 & 111 \\
\hline $\mathrm{H}, \mathrm{kN}$ & 913 & 920 & 0.99 \\
\hline Mc,l kNm & 181.3 & 170.5 & 1.06 \\
\hline $\mathrm{Mc}, \mathrm{r} \mathrm{kNm}$ & -179.8 & -169.2 & 1.06 \\
\hline$\sigma_{c, l}, \mathrm{MPa}$ & 103.2 & 95.6 & 1.07 \\
\hline$\sigma_{c, r}, \mathrm{MPa}$ & -87.1 & -81.3 & 1.07 \\
\hline $\mathrm{Mb}, 1 \mathrm{kNm}$ & 182.2 & 172.1 & 1.06 \\
\hline $\mathrm{Mb}, \mathrm{r} \mathrm{kNm}$ & -181.1 & 170.3 & 1.06 \\
\hline$\sigma_{b, l}, \mathrm{MPa}$ & 121.4 & 114.3 & 1.06 \\
\hline$\sigma_{b, r}, \mathrm{MPa}$ & -120.8 & -113.8 & 1.06 \\
\hline
\end{tabular}

There: $\Delta f_{p}$ - the displacement in the middle of the bridge span under the effect of the live load; $\mathrm{H}-$ the thrust of the cable; Mc,max the maximum bending moment of the rigid cable; $\mathrm{Mb}$, max - the maximum bending moment of the stiffening girder; $\sigma_{c, \text { max }}-$ the maximum stress of the rigid cable; $\sigma_{b, \max }-$ the maximum stress of the stiffening girder; $w_{l}$ - the maximum displacement of the loaded part of the bridge; $w_{r}$ - the maximum displacement of the unloaded part of the bridge; Mc, l - the bending moment of the rigid cable (loaded part of the bridge); Mc,r - the bending moment of the rigid cable (unloaded part of the bridge); $\sigma_{c, l}-$ the stress of the rigid cable (loaded part of the bridge); $\sigma_{c, r}$ - the stress of the rigid cable (unloaded part of the bridge); Mb,l - the bending moment of the stiffening girder (loaded part of the bridge); $\mathrm{Mb}, \mathrm{r}$ - the bending moment of the stiffening girder (unloaded part of the bridge); $\sigma_{b, l}-$ the stress of the stiffening girder (loaded part of the bridge); $\sigma_{b, r}$ - the stress of the stiffening girder (unloaded part of the bridge).

At the second stage of calculation, the internal force of the suspension bridge under the effect of the dead load is attributed to the elements of the bridge applying the function of Initial Element Forces. The displacement in the middle of the bridge span under the effect of the dead load equals $\Delta f_{g}=0$. Next, the bridge is loaded with the live load, and the final stress/strain state of the bridge is determined.

A comparison of calculation results is presented in Table 1.

The provided results demonstrate the sufficient accuracy of the worked out methodology. Under symmetric loading, errors in the displacement at the span centre and in the bending moments, maximum strain of the rigid cable and the stiffening girder do not exceed $5 \%$ and those in thrust make $1 \%$. Under asymmetric loading, the accuracy of the methodology is slightly lower. The maximum errors in the displacement do not exceed $13 \%$ and the errors in the bending moments, strain of the cable and stiffening girder make $7 \%$.

\section{Conclusions}

The paper analyses the asymmetric single-pylon suspension bridge with rigid cables and develops the methodology for calculating the asymmetric single-pylon suspen- sion bridge under the effect of symmetric and asymmetric loading. The performed numerical simulation has determined the accuracy of the proposed calculation methodology. The accuracy of the analytical expressions provided has been found to be sufficient. Under symmetric loading, difference in numerical simulation results do not exceed $5 \%$. Under asymmetric loading, the difference between the results obtained during numerical simulation and the applied analytical expressions do not exceed $13 \%$.

\section{References}

Arco, C. D., \& Aparicio, C. (2001). Preliminary static analysis of suspension bridges. Engineering Structures, 23(9), 1096-1103. https://doi.org/10.1016/S0141-0296(01)00009-8

Caballero, A., \& Pose, M. (2010). Local bending stresses in stay cables with an elastic guide. Structural Engineering International, 20(3), 254-259. https://doi.org/10.2749/101686610792016745

Clemente, P., Nicolosi, G., \& Raithel, A. (2000). Preliminary design of very long-span suspension bridges. Engineering Structures, 22(12), 1699-1706.

https://doi.org/10.1016/S0141-0296(99)00112-1

Furst, A., Marti, P., \& Ganz, H. (2001). Bending of stay cables. Structural Engineering International, 11(1), 42-46(5). https://doi.org/10.2749/101686601780324313

Gimsing, N. J., \& Georgakis, Ch. T. (2012). Cable supported bridges: Concept and design ( $3^{\text {rd }}$ ed.). John Wiley \& Sons. https://doi.org/10.1002/9781119978237 
Goremkins, V., Rocens, K., Serdjuks, D., \& Sliseris, J. (2013). Simplified method of determination of natural-vibration frequencies of prestressed suspension bridge. In Procedia Engineering 57 of 11th International Conference on Modern Building Materials, Structures and Techniques, MBMST 2013 (pp. 343-352). https://doi.org/10.1016/j.proeng.2013.04.046

Goremkins, V., Rocens, K., \& Serdjuks, D. (2012). Decreasing displacements of prestressed suspension bridge. Journal of Civil Engineering and Management, 18(6), 858-866.

https://doi.org/10.3846/13923730.2012.720936

Grigorjeva, T., Juozapaitis, A., \& Kamaitis, Z. (2010a). Static analysis and simplified design of suspension bridges having various rigidity of cables. Journal of Civil Engineering and Management: International Research and Achievements, 16(3), 363-371. https://doi.org/10.3846/jcem.2010.41

Grigorjeva, T., Juozapaitis, A., \& Kamaitis, Z. (2010b). Influence of construction method on the behaviour of suspension bridges with main rigid cables. In Selected Papers of 10th International Conference Modern Building Materials, Structures and Techniques (pp. 628-634). Technika.

Grigorjeva, T., \& Juozapaitis, A. (2013). Revised engineering method for analysis of behavior of suspension bridge with rigid cables and some aspects of numerical modelling. Procedia Engineering, 57, 364-371.

https://doi.org/10.1016/j.proeng.2013.04.048

Idnurm, J. (2006). Descrete Analysis Method for Suspension Bridges. The Baltic Journal of Road and Bridge Engineering, 1(2), 115-119.

Jennings, A. (1987). Deflection theory analysis of different cable profiles for suspension bridges. Engineering Structures, 9, 84-94. https://doi.org/10.1016/0141-0296(87)90002-2

Juozapaitis, A., Merkevičius, T., Daniūnas, A., Kliukas, R., Sandovič, G., \& Lukoševičiene, O. (2015). Analysis of innovative two-span suspension bridges. The Baltic Journal of Road and Bridge Engineering, 10(3), 269-275.

https://doi.org/10.3846/bjrbe.2015.34

Juozapaitis, A., Kliukas, R., Sandovič, G., Lukoševičienè, O., \& Merkevičius, T. (2013). Analysis of modern three-span suspension bridges with stiff in bending cables. The Baltic Journal of Road and Bridge Engineering, 8(3), 205-211.

https://doi.org/10.3846/bjrbe.2013.26

Juozapaitis, A., Idnurm, S., Kaklauskas, G., Idnurm, J., \& Gribniak, V. (2010). Non-linear analysis of suspension bridges with flexible and rigid cables. Journal of Civil Engineering and Management, 16(1), 149-154.

https://doi.org/10.3846/jcem.2010.14

Juozapaitis, A., \& Norkus, A. (2007). Shape determinating of a loaded cable via total displacements. Technological and Economic Development of Economy, 11(4), 283-291. https://doi.org/10.3846/13928619.2005.9637709

Juozapaitis, A., \& Norkus, A. (2005). Determination of rational parameters for the advanced structure of a pedestrian suspension steel bridge. The Baltic Journal of Road and Bridge Engineering, 2(4), 173-181.

Kiisa, M., Idnurm, J., \& Idnurm, S. (2012). Descrete analysis of elastic cables. The Baltic Journal of Road and Bridge Engineering, 7(2), 98-103. https://doi.org/10.3846/bjrbe.2012.14

Kim, S. E., \& Thai, H.-T. (2010). Nonlinear inelastic dynamic analysis of suspension bridges. Engineering Structures, 32(12), 3845-3856. https://doi.org/10.1016/j.engstruct.2010.08.027

Kulbach, V. (2007). Cable structures. Design and analysis. Estonian Academy Publisher.

Ryall, M., Parke, G., \& Harding, J. (2000). The manual of bridges engineering. Tomas Telford Ltd.
Prato, C. A., \& Ceballos, M. A. (2003). Dynamic bending stresses near the ends of parallel bundle stay cables. Structural Engineering International, 13(1), 42-46.

https://doi.org/10.2749/101686603777965008

Sandovič, G., Juozapaitis, A., \& Kliukas, R. (2011). Simplified engineering method of suspension two-span pedestrian steel bridges with flexible and rigid cables under action of assymetrical loads. The Baltic Journal of Road and Bridge Engineering, 6(4), 267-273. https://doi.org/10.3846/bjrbe.2011.34

Sousa, R., Souza, R. M., Figueiredo, F. P., \& Menezes, I. F. (2011). The influence of bending and shear stiffness and rotational inertia in vibration of cables: an analytical approach. Engineering Structures, 33(3), 689-695.

https://doi.org/10.1016/j.engstruct.2010.11.026

Strasky, J. (2005). Stress-ribbon and supported cable pedestrian bridges. Tomas Telford Ltd.

Treyssede, F. (2010). Vibration analysis of horizontal self-weighted beams and cables with bending stiffness subject to thermal loads. Journal of Sound and Vibration, 329(9), 1536-1552. https://doi.org/10.1016/j.jsv.2009.11.018

Troyano, L. F. (2003). Bridge engineering: A global perspective. Tomas Telford Ltd. https://doi.org/10.1680/beagp.32156

Wollmann, G. P. (2001). Preliminary analysis of suspension bridges. Journal of Bridge Engineering, 6(4), 227-233. https://doi.org/10.1061/(ASCE)1084-0702(2001)6:4(227) 